\title{
Enantioselective synthesis of atropisomeric indoles via iron catalysed oxidative cross-coupling
}

\author{
Richard R. Surgenor ${ }^{1}$, Xiangqian Liu ${ }^{1}$, William Myers ${ }^{2} \&$ Martin D. Smith ${ }^{1 *}$ \\ ${ }^{1}$ Chemistry Research Laboratory, University of Oxford, 12 Mansfield Road, Oxford, OX1 3TA, UK. \\ ${ }^{2}$ Inorganic Chemistry Laboratory, University of Oxford, South Parks Road, Oxford, OX1 3QR, UK.
}

E-mail: martin.smith@chem.ox.ac.uk; homepage: http://msmith.chem.ox.ac.uk/

\begin{abstract}
Heterobiaryl compounds that exhibit axial chirality are of increasing value and interest across several fields, but direct oxidative methods for their enantioselective synthesis are elusive. Here we disclose that an iron catalyst in the presence of a chiral PyBOX ligand and an oxidant enables direct coupling between naphthols and indoles to yield atropisomeric heterobiaryl compounds with high levels of enantioselectivity. The reaction exhibits remarkable chemoselectivity and exclusively yields cross-coupled products without competing homocoupling. Mechanistic investigations enable us to postulate that the reaction proceeds through selective formation of an indole radical which is trapped by a chiral iron naphthoate in a radical-anion type coupling process. We envision that this simple, cheap, and sustainable catalytic manifold will facilitate access to a range of heterobiaryl compounds and enable their applications across the fields of materials science, medicinal chemistry, and catalysis.
\end{abstract}

Atropisomeric biaryls comprise a privileged class of compounds whose applications span the fields of medicinal chemistry, catalysis and materials science; as such, a panoply of elegant and efficient methods have been developed for their synthesis ${ }^{1}$. The most convergent route to biaryls is generally the transition metal mediated cross-coupling of two partners ${ }^{2,3}$ (although significant advances in metal-free methods have been demonstrated recently) ${ }^{4}$. Whilst this strategy generally results in cross-coupled products in good yields and predictable levels of chemo- and regioselectivity, these advantages may be offset by the requirement to synthesize two specifically functionalized coupling partners (Figure 1a) $)^{5}$. In principle, oxidative coupling represents a more direct, atom economic and environmentally benign approach as it creates the desired aryl-aryl linkage from two $\mathrm{C}-\mathrm{H}$ bonds $\mathrm{s}^{6,7}$. This realization has led to a significant number of oxidative homo-coupling procedures that can generate $C_{2}$-symmetric BINOL-like structures in an enantioselective fashion. These include reactions mediated by transition metals including copper ${ }^{8-10}$, iron $^{11}$ and vanadium, ${ }^{12}$ amongst others. However, in the absence of specific functional groups, controlling the regio-, chemo- and enantioselectivity of the corresponding hetero-couplings remains a formidable challenge, and successful examples have been limited to the synthesis of BINOL or NOBIN type scaffolds ${ }^{13-16}$. In particular, Katsuki demonstrated that iron salan complexes are effective in the enantioselective heterocoupling of naphthols ${ }^{17}$, and Pappo showed that chiral iron phosphate complexes act as effective precatalysts for the enantioselective synthesis of non $C_{2}$-symmetric BINOLs (Figure $\left.1 \mathrm{~b}\right)^{18}$. We considered whether this oxidative cross-coupling approach could be used in the development of a method for the enantioselective synthesis of axially chiral indoles, which are emerging as a valuable member of the atropisomeric biaryl family ${ }^{19-21}$. 


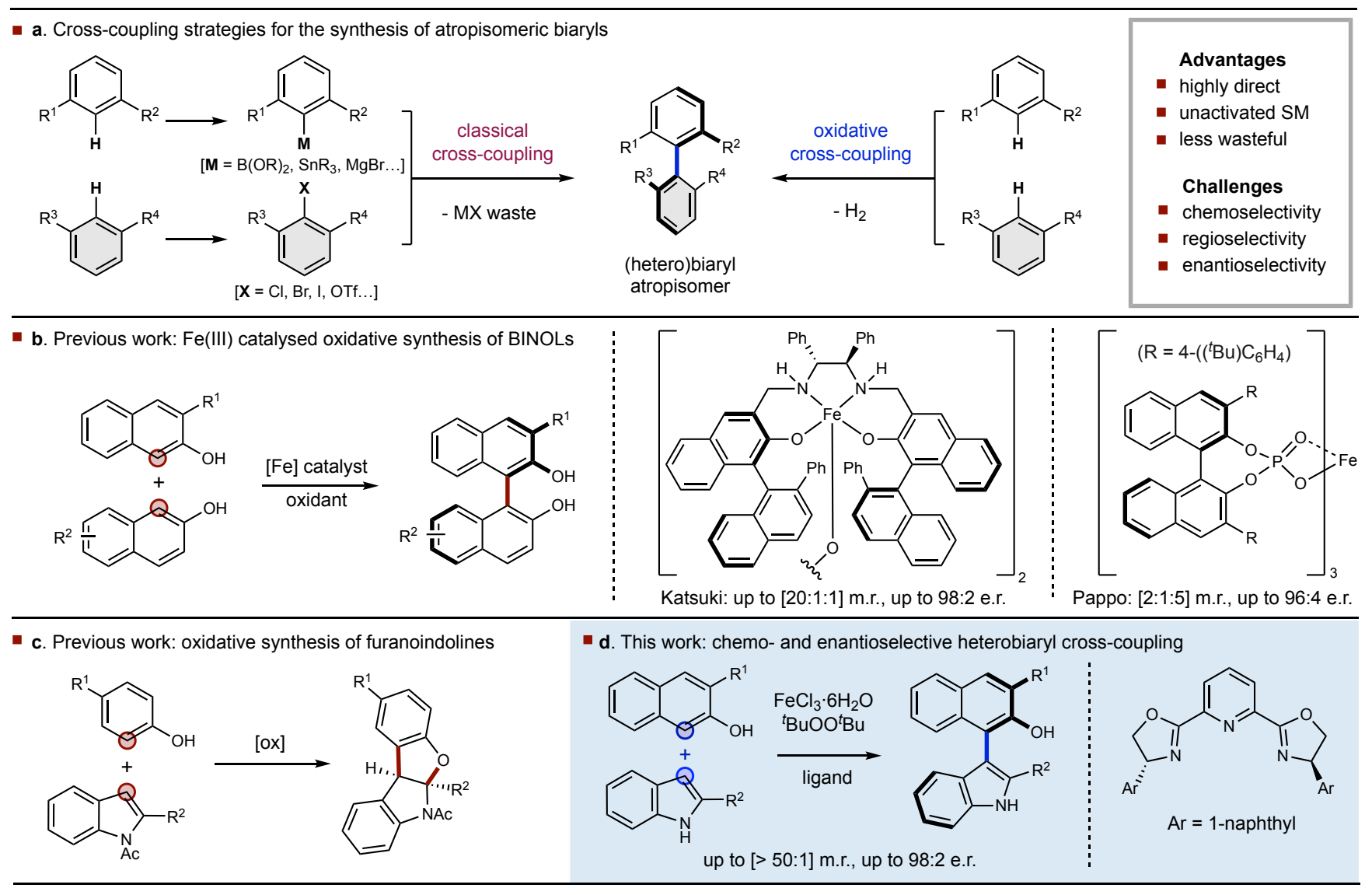

Figure 1. Oxidative cross coupling reactions. a Cross-coupling strategies to assemble biaryls include transition metal catalysed crosscoupling between specifically functionalized partners and direct oxidative cross-coupling where the desired aryl-aryl linkage is formed from two C-H bonds. b Previous work: iron catalysed enantioselective oxidative syntheses of $C_{1}$-symmetric BINOLs. m.r. $=$ molar ratio of heterocoupled : homo-coupled : homo-coupled products. e.r. = enantiomeric ratio. c Previous work: synthesis of benzofuranoindolines by oxidative coupling has been achieved by a variety of different methods $([\mathrm{ox}]=$ oxidant). $\mathbf{d}$ This work: direct chemo- and enantioselective cross-coupling to form configurationally stable heterobiaryls.

Oxidative cross-couplings between indoles and phenols have been disclosed in the synthesis of benzofuranoindolines ${ }^{22,23}$, which are key components of complex natural products including diazonamide and phalarine (Figure 1c). A range of oxidants (including hypervalent iodine reagents ${ }^{24}$, iron(III) salts ${ }^{25}$ and electrochemistry ${ }^{26}$ ) have been successfully employed in such cross-coupling reactions, some of which demonstrate exceptional levels of cross-coupling selectivity. We reasoned that if the steric bulk on the phenol, and particularly the indole component was increased, the overall process could favour rearomatization rather than [3+2] annulation to generate an atropisomeric heterobiaryl (Figure 1d). We began by screening a range of oxidants for the reaction between a 1:1.1 mixture of 2-naphthol and 2-methylindole. In a preliminary screen of conditions (see supplementary information S25), hypervalent iodine reagents and $\mathrm{VOF}_{3}{ }^{27}$ were poorly selective for the desired heterocoupling process, whilst $[\mathrm{Cu}(\mathrm{OH}) \cdot \mathrm{TMEDA}]_{2} \mathrm{Cl}_{2}$ in air favoured formation of the homocoupled BINOL product. We were delighted to find that catalytic iron(III) chloride in 1,1,1,3,3,3-hexafluoroisopropanol (HFIP) with di-tertbutylperoxide as co-oxidant ${ }^{28,29}$, gave exclusively the cross-coupled heterobiaryl product $3 \mathbf{a}$ in $96 \%$ yield, as a single indole C-3 regioisomer (Table 1, entry 1). The remarkable selectivity of this reaction is noteworthy: we do not observe any trace of the potential homocoupled BINOL 4 or 3,3'-bisindole side 5 products. The rotational barrier of this product was determined to be $\Delta \mathrm{G}_{353 \mathrm{~K}}^{\ddagger}=26.0 \mathrm{kcal} \mathrm{mol}^{-1}$; the potential configurational lability of this material (a class 2 atropisomer $)^{30}$ motivated us to continue to investigate compounds with higher rotational barriers. We reasoned that a larger substituent at the C-2 position of the indole would significantly increase the barrier to rotation of the product. Hence, we subjected 2-tert-butylindole to the same reaction conditions; this afforded $39 \%$ of the desired heterocoupled product $\mathbf{3 b}$ in addition to a $48 \%$ yield of the homocoupled BINOL product (Table 1, entry 2). One strategy to mitigate homocoupling is to modulate the oxidation potential and nucleophilicity of the phenol component through the installation of an electron withdrawing group ${ }^{31-33}$. When a naphthol bearing a C-3 methyl ester was used 


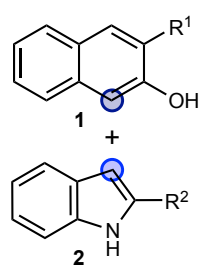

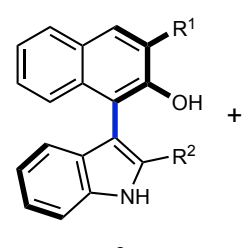

3

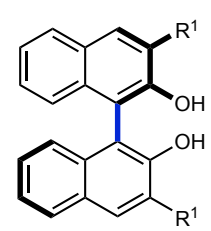

4

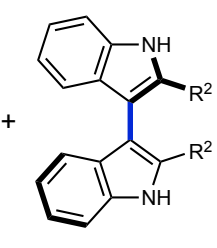

5 (not observed)

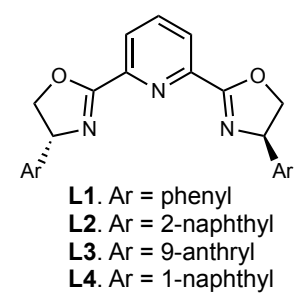

\begin{tabular}{|c|c|c|c|c|c|c|c|c|}
\hline Entry & [Fe] salt & Ligand & Heterobiaryl & $\mathbf{R}^{1}$ & $\mathbf{R}^{2}$ & Yield of 3 (4) & [3:4] m.r. & e.r. of 3 \\
\hline $1^{a}$ & $\mathrm{FeCl}_{3}$ & none & $3 a$ & $\mathrm{H}$ & $\mathrm{Me}$ & $96 \%$ & $>50: 1$ & $\mathrm{n} / \mathrm{a}$ \\
\hline $2^{a}$ & $\mathrm{FeCl}_{3}$ & none & $3 b$ & $\mathrm{H}$ & ${ }^{t} \mathrm{Bu}$ & $39 \%(48 \%)$ & $5: 6$ & $\mathrm{n} / \mathrm{a}$ \\
\hline $3^{a}$ & $\mathrm{FeCl}_{3}$ & none & $3 c$ & $\mathrm{CO}_{2} \mathrm{Me}$ & ${ }^{\mathrm{t}} \mathrm{Bu}$ & $89 \%$ & $>50: 1$ & $\mathrm{n} / \mathrm{a}$ \\
\hline $4^{a}$ & $\mathrm{FeCl}_{3}$ & L1 & $3 c$ & $\mathrm{CO}_{2} \mathrm{Me}$ & tBu & $56 \%$ & $>50: 1$ & $60: 40$ \\
\hline $5^{a}$ & $\mathrm{FeCl}_{3} \cdot 6 \mathrm{H}_{2} \mathrm{O}$ & L1 & $3 c$ & $\mathrm{CO}_{2} \mathrm{Me}$ & ${ }^{t} \mathrm{Bu}$ & $80 \%$ & $>50: 1$ & 70:30 \\
\hline 6 & $\mathrm{FeCl}_{3} \cdot 6 \mathrm{H}_{2} \mathrm{O}$ & L1 & $3 c$ & $\mathrm{CO}_{2} \mathrm{Me}$ & ${ }^{\mathrm{t}} \mathrm{Bu}$ & $60 \%$ & $>50: 1$ & $75: 25$ \\
\hline 7 & $\mathrm{FeCl}_{3} \cdot 6 \mathrm{H}_{2} \mathrm{O}$ & L1 & $3 d$ & $\mathrm{CO}_{2} \mathrm{Ph}$ & tBu & $67 \%$ & $>50: 1$ & $84: 16$ \\
\hline 8 & $\mathrm{FeCl}_{3} \cdot 6 \mathrm{H}_{2} \mathrm{O}$ & L2 & $3 d$ & $\mathrm{CO}_{2} \mathrm{Ph}$ & 'Bu & $63 \%$ & $>50: 1$ & $88: 12$ \\
\hline 9 & $\mathrm{FeCl}_{3} \cdot 6 \mathrm{H}_{2} \mathrm{O}$ & L3 & $3 d$ & $\mathrm{CO}_{2} \mathrm{Ph}$ & tBu & $58 \%$ & $>50: 1$ & $75: 25$ \\
\hline 10 & $\mathrm{FeCl}_{3} \cdot 6 \mathrm{H}_{2} \mathrm{O}$ & L4 & $3 d$ & $\mathrm{CO}_{2} \mathrm{Ph}$ & 'Bu & $71 \%$ & $>50: 1$ & $89: 11$ \\
\hline $11^{b}$ & $\mathrm{FeCl}_{3} \cdot 6 \mathrm{H}_{2} \mathrm{O}$ & L4 & $3 d$ & $\mathrm{CO}_{2} \mathrm{Ph}$ & tBu & $75 \%$ & $>50: 1$ & $90: 10$ \\
\hline $12^{b}$ & $\mathrm{FeCl}_{3} \cdot 6 \mathrm{H}_{2} \mathrm{O}$ & L4 & $3 e$ & $\mathrm{CO}_{2} \mathrm{R}^{*}$ & tBu & $63 \%$ & $>50: 1$ & $92: 8$ \\
\hline $13^{b, c, d}$ & $\mathrm{FeCl}_{3} \cdot 6 \mathrm{H}_{2} \mathrm{O}$ & L4 & $3 e$ & $\mathrm{CO}_{2} \mathrm{R}^{*}$ & tBu & $91 \%^{e}$ & $>50: 1$ & $94: 6$ \\
\hline
\end{tabular}

in the cross-coupling reaction with 2-tert-butylindole without a large excess of either component, exclusive formation the cross-coupled product $3 \mathbf{c}$ was observed in $89 \%$ yield (Table 1, entry 3 ). The rotational barrier of this molecule setermined to be $\Delta \mathrm{G}_{413 \mathrm{~K}}^{\ddagger}=38.3 \mathrm{kcal} \mathrm{mol}^{-1}$; a barrier of this magnitude essentially precludes racemisation unless forcing thermal conditions are employed.

Table 1: Reaction Optimization. Conditions: performed on $0.1 \mathrm{mmol} \mathrm{scale,} \mathrm{Fe} \mathrm{salt} \mathrm{(10} \mathrm{mol \% ),} \mathrm{ligand} \mathrm{(11} \mathrm{mol} \mathrm{\% )} \mathrm{naphthol} \mathrm{(1.0} \mathrm{eq.),} \mathrm{indole}$ (1.1 eq.), ${ }^{t} \mathrm{BuOO}^{t} \mathrm{Bu}$ (1.2 eq.), DCE/HFIP, 1:1 (v/v); [naphthol] = $0.1 \mathrm{M}$, r.t., 16 h. Yields and molar ratios (m.r.) of products determined by quantitative ${ }^{1} \mathrm{H}$ NMR spectroscopy using 1,3,5-trimethoxybenzene as internal standard. Numbers in parentheses refer to yields of homocoupled $(\mathrm{BINOL})$ product; e.r. $=$ enantiomeric ratio, determined by chiral stationary phase HPLC; $\mathrm{R}^{*}=2$-isopropylphenyl; ${ }^{a}[\mathrm{naphthol}]=0.2 \mathrm{M}$. ${ }^{b} 12 \mathrm{~mol} \%$ ligand used. ${ }^{c} \mathrm{FeCl}_{3} \cdot 6 \mathrm{H}_{2} \mathrm{O}$ pulverized by sonication in DCE for $30 \mathrm{~min}$ before adding ligand. ${ }^{d}$ indole (1.5 eq.), ${ }^{t} \mathrm{BuOO}{ }^{t} \mathrm{Bu}(1.5$ eq. $)$, 48 h. $^{e}$ isolated yield.

With an effective catalyst system in hand for the chemoselective production of the desired heterobiaryl, we focused on selection of an appropriate chiral ligand to facilitate an atropselective reaction. We discovered that ligands of the bis-oxazoline family were viable for an enantioselective transformation, with phenyl substituted PyBOX ligand L1 affording the heterocoupled product in the presence of anhydrous iron(III) chloride in a modest 60:40 e.r. ${ }^{34}$ Both yield and e.r. were improved ( $80 \%$ yield at 75:25 e.r.) on switching to the hexahydrate salt (which is both cheaper and easier to handle; Table 1, entry 5). We recognized that the group at C-3 of the naphthol partner might also have an impact beyond enhancing chemoselectivity and found that e.r. of 3d increased (to 84:16) with a larger (phenyl) ester group. We subsequently explored different PyBOX ligands in combination with changes at the C-3 ester, finding that the combination of 1-naphthyl substituted PyBOX ligand $\mathbf{L} 4$ with a 2-isopropylphenyl ester substrate afforded the heterobiaryl product $3 \mathrm{e}$ in $63 \%$ yield and $92: 8$ e.r. (Table 1, entry 12). Modulation of reaction time, an increase in the quantity of ligand (to $12 \mathrm{~mol} \%$ ) and indole (to 1.5 eq.) and sonication of the Fe salt prior to ligand addition all continued the aggregation of marginal gains to ultimately afford the desired heterocoupled biaryl product in $91 \%$ yield and 94:6 e.r. With an optimized set of reaction conditions, we explored the substrate scope for the reaction (Figure 2). In all cases, the mass balance is accounted for as unreacted naphthol starting material, and the 3,3'bisindole product 5 is not observed. 

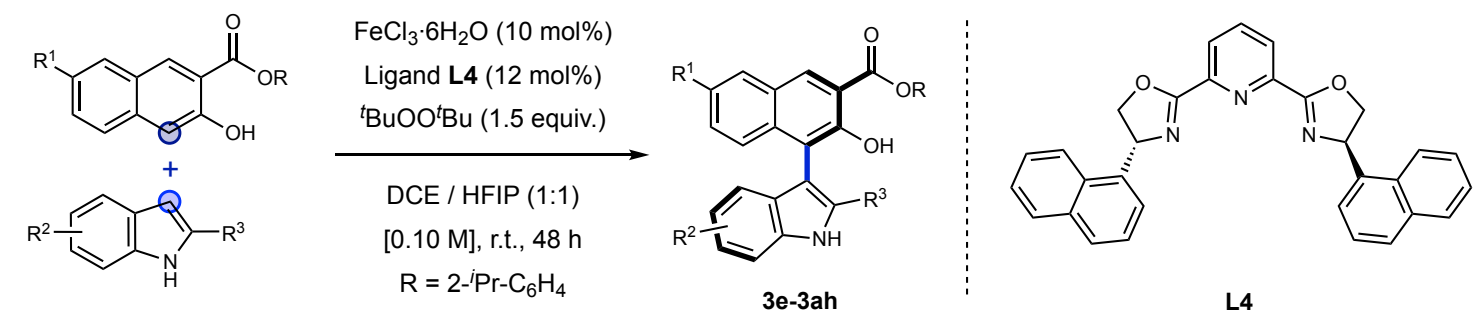

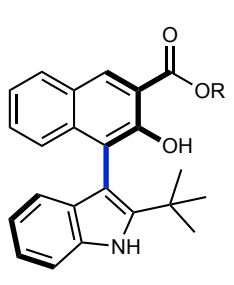

3e $91 \%$; (93\%) [>50:1]; $94: 6$ e.r.

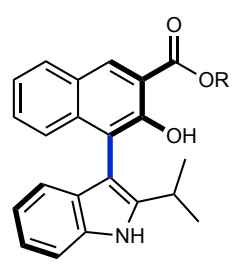

3k 93\%; (98\%) [>50:1]; $60: 40$ e.r.

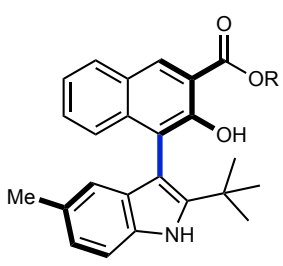

3q 78\%; (89\%) [>50:1]; $93: 7$ e.r.

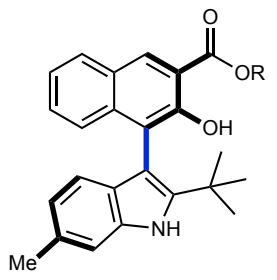

3w 79\%; (98\%) [>50:1]; $88: 12$ e.r.

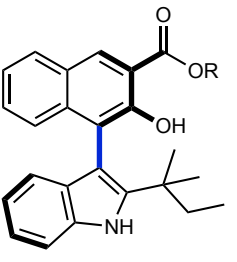

3f $83 \%$; (92\%) [>50:1]; 95:5 e.r.

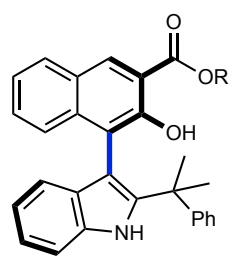

31 $80 \%$; (91\%) [>50:1]; $96: 4$ e.r.

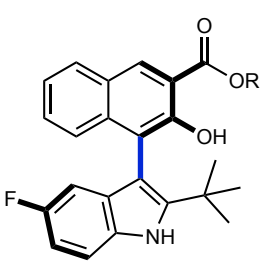

3r 60\%; (90\%) [>50:1]; $92: 8$ e.r.<smiles>[R20]C(=O)c1cc2ccccc2c(-c2c(C(C)(C)C)[nH]c3cc(F)ccc23)c1O</smiles>

$3 \times 63 \%$; (100\%) [45:1]; 84:16 e.r.

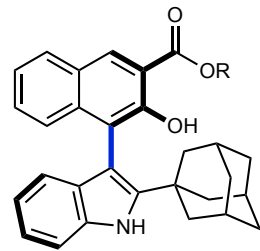

3g $71 \%$; (88\%) [>50:1]; $91: 9$ e.r.<smiles>CC(C)(c1ccccc1)c1[nH]c2ccccc2c1-c1c(O)c(C(=O)Oc2ccccc2)cc2ccccc12</smiles>

3 m 85\%; (90\%) [>50:1]; $98: 2$ e.r.

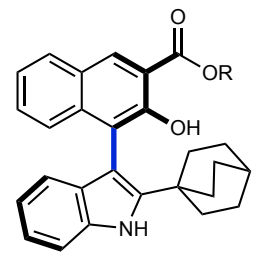

3h $80 \%$; (86\%) [>50:1]; $86: 14$ e.r.

3n $80 \%$; (94\%) [>50:1]; $90: 10$ e.r.

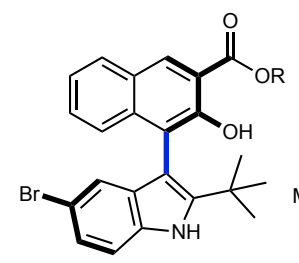

3s $40 \%$; $(87 \%)$

[21:1]; $90: 10$ e.r.<smiles>[R2]C(=O)c1cc2ccccc2c(-c2c(C(C)(C)C)[nH]c3cc(Cl)ccc23)c1O</smiles>

3y $56 \%$; (86\%)

[36:1]; 89:11 e.r.<smiles>[R]OC(=O)c1cc2ccccc2c(-c2c(C3(C)CCCC3)[nH]c3ccccc23)c1O</smiles>

3i $75 \%$; (95\%) [>50:1]; $94: 6$ e.r.<smiles>[R]OC(=O)c1cc2ccccc2c(-c2c(C(C)(C)C)[nH]c3cccc(Cl)c23)c1O</smiles>

3o $82 \%$; (90\%) [>50:1]; $94: 6$ e.r.<smiles>[R]OC(=O)c1cc2ccccc2c(-c2c(C(C)(C)C)[nH]c3ccc(C)cc23)c1O</smiles>

3u 28\%; (97\%)

[17:1]; 72:28 e.r.

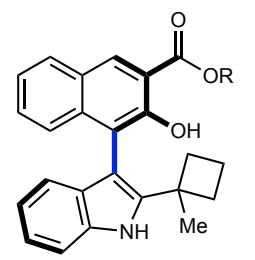

3j 90\%; (94\%) [>50:1]; $96: 4$ e.r.<smiles>[R]OC(=O)c1cc2ccccc2c(-c2c(C(C)(C)C)[nH]c3ccc(OC)cc23)c1O</smiles>

3p 97\%; (99\%) [>50:1]; $93: 7$ e.r.<smiles>[R7]C(=O)c1cc2ccccc2c(-c2c(C(C)(C)C)[nH]c3ccc(C#N)cc23)c1O</smiles>

3v 13\%; (97\%)

[>50:1]; 85:15 e.r.

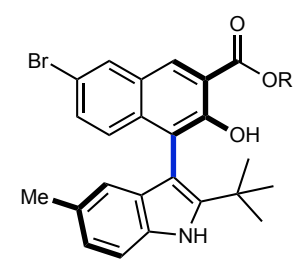

3ac $67 \%$; (89\%) [>50:1]; 88:12 e.r.<smiles>COc1ccc2[nH]c(C(C)(C)C)c(-c3c(O)c(C(=O)[O-])cc4cc(Br)ccc34)c2c1</smiles>

3ad $76 \%$; (92\%) [>50:1]; $91: 9$ e.r.<smiles>CC(C)(C)Cc1[nH]c2ccccc2c1-c1cc2ccc(Br)cc2cc1C(=O)O</smiles>

3ae 54\%; (87\%) [>50:1]; $95: 5$ e.r.<smiles>Cc1cccc2c1[nH]c1c(C(=O)O)cc3ccccc3c12</smiles>

3z 85\%; (90\%) [>50:1]; $86: 14$ e.r.<smiles>[R]OC(=O)c1cc2cc(Br)ccc2c(-c2c(C(C)(C)C)[nH]c3ccccc23)c1O</smiles>

3aa 66\%; (92\%) [>50:1]; $93: 7$ e.r.<smiles>[R]OC(=O)c1cc2cc(-c3ccccc3)ccc2c(-c2c(C(C)(C)C)[nH]c3ccccc23)c1O</smiles>

3ab 52\%; (86\%) [>50:1]; 90:10 e.r.

Figure 2. Scope of Enantioselective Indole-Naphthol Coupling. Reaction Conditions: All performed on $0.1 \mathrm{mmol} \mathrm{scale:} \mathrm{FeCl}_{3} \cdot 6 \mathrm{H}_{2} \mathrm{O}$ (10 mol\%), ligand L4 (12 mol\%) naphthol (1.0 eq.), indole (1.5 eq.), ${ }^{t} \mathrm{BuOO}{ }^{t} \mathrm{Bu}$ (1.5 eq.), DCE/HFIP, 1:1 (v/v); [naphthol] = 0.10 M, r.t., 48 h. Yields refer to isolated and purified material. Figures in parentheses indicate yields based upon remaining naphthol starting material determined by quantitative ${ }^{1} \mathrm{H}$ NMR spectroscopy using 1,3,5-trimethoxybenzene as internal standard. Figures in square brackets represent the ratio of [heterocoupled biaryl 3 : homocoupled BINOL 4] determined by quantitative ${ }^{1} \mathrm{H}$ NMR spectroscopy; e.r. = enantiomeric ratio, determined by chiral stationary phase HPLC. 
The size of the indole C-2 substituent is important in determining the rotational barrier of the biaryl products and hence we explored substrates with sterically hindered groups in this position. An indole bearing a tert-amyl group couples effectively to afford 3f in $83 \%$ yield and high enantioselectivity $(95: 5$ er) with no trace of other products. Similarly, 2-adamantyl and bicyclo[2.2.2.] ]octane groups are also tolerated to afford $\mathbf{3 g}$ (71\% yield; $91: 9$ e.r.) and $\mathbf{3 h}$ (80\% yield; $86: 14$ e.r.) with good levels of selectivity. Other cycloalkyl groups including 2-methylcyclopentyl and 2-methylcyclobutyl are also effective in this reaction, affording biaryls $\mathbf{3 i}$ (75\% yield, $94: 6$ e.r.) and $\mathbf{3 j}$ (90\% yield, 96:4 e.r.) respectively. Changing to a smaller group at this position such as iso-propyl does not impact cross-coupling efficiency or chemoselectivity (affording 3k in 93\% yield as the sole product) but does lead to a significant reduction in enantioselectivity (to 60:40 e.r.). Enantioselectivity is restored with an indole bearing an $\alpha$, $\alpha$-dimethylbenzyl group (to afford 31 in $80 \%$ yield and $96: 4$ e.r.). A phenyl ester on the naphthol is also a viable and more selective substrate in this reaction, generating $\mathbf{3 m}$ in $85 \%$ yield and 98:2 e.r. We subsequently explored substitution around the indole ring, and indoles bearing halogens such as fluorine or chlorine both undergo oxidation without incident to afford biaryls 3n (80\% yield, 90:10 e.r.) and 3o (82\% yield, 94:6 e.r.) respectively. We next examined C-5 substitution on the indole reactant. Electron donating groups such as methoxy are highly effective, affording biaryl $\mathbf{3 p}$ in 97\% yield and 93:7 e.r. 5-Alkyl groups are also well tolerated, affording biaryl 3q in 78\% yield and 93:7 e.r. We observed that electron withdrawing groups such as fluorine in this position led to lower conversions as in $\mathbf{3 r}$ (60\% yield, 92:8 e.r.), and considered that this may provide some insight into the mechanism of this transformation. Consequently, we decided to study a series of different electron withdrawing groups in this position to evaluate the impact on the reaction. A 5-bromo substituent led to biaryl formation $3 \mathrm{~s}$ in only $40 \%$ yield, but with a relatively high enantioselectivity (90:10 e.r.). More powerful electron withdrawing groups on the indole coupling partner led to the generation of biaryls bearing an ester $3 \mathbf{t}$ (40\% yield, $85: 15$ e.r.), a trifluoromethyl group $3 \mathbf{u}$ (28\% yield, $72: 28$ e.r.) or a cyano group $3 \mathbf{v}$ (13\% yield, $85: 15$ e.r.) in lower yields and enantioselectivities; we also saw a reduction in chemoselectivity as manifested by the competitive formation of small quantities of the $C_{2}$-symmetric BINOL product. It is clear that the electronic nature of the substituents on the indole has an impact on conversion and selectivity. C-6 substitution is tolerated albeit with slightly lower enantioselectivity: 6-methyl 3w (79\% yield, 88:12 e.r.), 6-fluoro 3x (63\% yield, 84:16 e.r.) and 6-chloro 3y (56\% yield, 89:11 e.r.) are all effectively produced. An indole bearing a $\mathrm{C}-7$ methyl group is also a competent partner in this reaction, leading to the corresponding biaryl $\mathbf{3 z}$ in $85 \%$ yield and 86:14 e.r. We next examined whether the introduction of different groups on the naphthol coupling partner was possible. A 6-bromo substituent coupled effectively to afford biaryl 3aa in 66\% yield and 93:7 e.r.; a more conjugating group in 6-phenyl was also successful to afford 3ab with lower conversion (52\% yield) and 90:10 e.r. We are able to accommodate groups on both coupling partners: a 6-methyl indole coupled with a 6-bromo naphthol to exclusively afford the hetero-coupled biaryl 3ac (67\% yield; $88: 12$ e.r.). This principle can be extended to the formation of different biaryls such as 3ad (76\% yield, $91: 9$ e.r.). Different substituents on the naphthol component can also be combined with different C-2 substituents on the indole component to afford an array of different products; these are exemplified by the formation of biaryl compounds bearing bromo 3ae (54\% yield, 95:5 e.r.), methoxy 3af (82\% yield, 92:8 e.r.), aryl 3ag (45\% yield, 95:5 e.r.) and alkyl 3ah (66\% yield, 93:7 e.r.) groups.

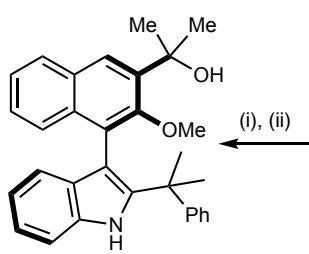

6

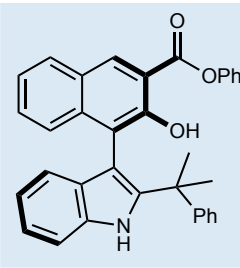

$3 \mathrm{~m}$

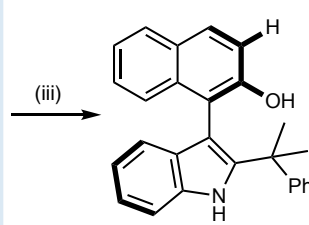

7

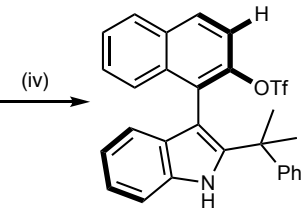

8

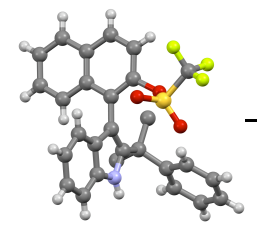

X-ray (CCDC 2090406)

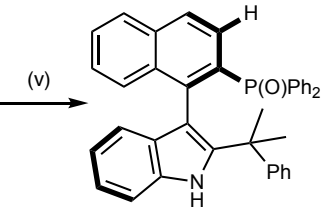

9

Figure 3: Chemoselective derivatizations. (i) $\mathrm{Me}_{2} \mathrm{SO}_{4}$ (1.5 eq.), $\mathrm{K}_{2} \mathrm{CO}_{3}$ (1.2 eq.), acetone, reflux, 24 h, $90 \%$ ( $97: 3$ e.r.). (ii) $\mathrm{MeMgCl}$ (3.0 eq.), THF, r.t. $-65{ }^{\circ} \mathrm{C}, 16$ h, 71\% (97:3 e.r.). (iii) $\mathrm{Pd}(\mathrm{OAc})_{2}$ (10 mol.\%), 1,2-bis(dicyclohexylphosphino)ethane (20 mol.\%), Et $3 \mathrm{SiH}(1.5$ eq.), toluene, $160{ }^{\circ} \mathrm{C}, 16$ h, $69 \%$ (97:3 e.r.). (iv) $\mathrm{Tf}_{2} \mathrm{O}$ (1.5 eq.), DIPEA (2.0 eq.), $\mathrm{CH}_{2} \mathrm{Cl}_{2}, 0{ }^{\circ} \mathrm{C}-$ r.t., 48 h, $94 \%$ (97:3 e.r.). (v) $\mathrm{Ph} 2 \mathrm{P}(\mathrm{O}) \mathrm{H}, \mathrm{Pd}(\mathrm{OAc})_{2}$ (10 mol.\%), 1,4-bis(diphenylphosphino)butane (20 mol.\%), DMSO, $120{ }^{\circ} \mathrm{C}, 96 \mathrm{~h}, 56 \%(94 \%$ BRSM, $97: 3$ e.r.).

The atropisomeric biaryl $\mathbf{3 m}$ contains a number of different functional groups, and to demonstrate their orthogonality, chemoselective derivatizations were implemented (Figure 3). The C-3 ester on the naphthol 3m (97:3 e.r.), which is implicated in the observed selectivity in the cross-coupling process, can be transformed into tertiary alcohol 6 which 
is valuable in catalysis by $O$-functionalization followed by the addition of an excess of Grignard reagent. The $\mathrm{C}-3$ ester group can also be conveniently removed by a palladium(II) catalysed reductive decarboxylation in the presence of stoichiometric triethylsilane to afford 7. Although this requires high temperatures, the magnitude of the aryl-aryl barrier to rotation enables this to be performed without compromising enantiointegrity. The phenol in 7 can be simply transformed into triflate $\mathbf{8}$; the absolute configuration of this compound was confirmed by X-ray crystallography. This compound can function as a divergent intermediate for a range of cross-coupling reactions, as exemplified by the formation of $\mathbf{9}$, through a palladium(II) coupling with diphenylphosphine oxide.

The majority of mechanisms proposed for Fe catalysed oxidative cross-couplings are based upon an $\mathrm{Fe}(\mathrm{III}) / \mathrm{Fe}(\mathrm{IV})$ cycle, which broadly parallel the accepted mechanisms for the operation of heme-containing enzymes ${ }^{35,36}$. Crosscoupling selectivity in non-heme systems are usually determined by differences in oxidation potentials that control which cross-coupling partner is oxidized preferentially, in conjunction with other parameters that influence nucleophilicity and acidity ${ }^{11,37}$. To probe the determinants of reactivity and selectivity in our system, we measured the oxidation potentials of 2-tert-butyl indole $(0.71 \mathrm{~V} \mathrm{vs} \mathrm{Ag} / \mathrm{AgCl})$ and 2-isopropylphenyl 3-hydroxy-2-naphthoate $(1.42 \mathrm{~V}$ vs $\mathrm{Ag} / \mathrm{AgCl})$ in HFIP. These measurements clearly show that in this case the indole is significantly easier to oxidize than the naphthol component. We also carried out a series of control experiments in an attempt to ascertain the roles of the $\mathrm{Fe}$ catalyst and the co-oxidant in our cross-selective reaction. Performing the reaction with $10 \mathrm{~mol} \%$ of Fe(III) catalyst/ligand but in the absence of any stoichiometric oxidant, we observed $6 \%$ of the cross-coupled product (90:10 e.r.). We subsequently performed a reaction with a stoichiometric amount of $\mathrm{Fe}(\mathrm{III})$ catalyst and ligand, again in the absence of any other oxidant; this led to isolation of the cross-coupled product in $47 \%$ of a $50 \%$ maximum yield (89:11 e.r.). The formation of highly enantioenriched products in the absence of ${ }^{t} \mathrm{BuOO}{ }^{t} \mathrm{Bu}$ demonstrates that an enantioselective $\mathrm{Fe}(\mathrm{III}) / \mathrm{Fe}$ (II) pathway is viable with the optimized $\mathrm{Fe}(\mathrm{III}) / \mathrm{PyBOX}$ combination. We also investigated whether the stoichiometric $\mathrm{Fe}(\mathrm{III}) / \mathrm{PyBOX}$ combination was able to oxidize 2isopropylphenyl 3-hydroxy-2-naphthoate; after $48 \mathrm{~h}$ we observed $18 \%$ of the $C_{2}$-symmetric BINOL. This lower conversion is consistent with the higher oxidation potential measured for the naphthol coupling partner but is distinct from Katsuki's Fe(III) salan system, which was shown be inert in the absence of oxygen ${ }^{38}$. To determine whether our oxidation state measurements were reflected by the presence of radical species in solution, we employed EPR spectroscopy (Figure $4 a)$. We were able to observe a species $(g=2.0051)$ in low spin concentration that we identified as the indole radical (by virtue of its characteristic ${ }^{14} \mathrm{~N}$ hyperfine signature) by stirring the indole in HFIP/DCE without precautions to exclude oxygen. In the presence of the $\mathrm{Fe}$ (III) catalyst, a different species also consistent with an indole radical ${ }^{39,40}$ can be observed $(\mathrm{g}=2.00265)$. This lacks the ${ }^{14} \mathrm{~N}$ hyperfine structure observed previously, most likely due to reduced nitrogen character in the wavefunction and rapid relaxation as a consequence of being proximal to the metal centre; no other radical species apart from Fe(III) were observable (see supplementary information S9697). We were also able to capture the indole radical species by the addition of trapping agents triethylphosphite and 5,5-dimethylpyrroline- $N$-oxide. This led to the observation of adducts of the proposed indole radical (by HRMS ESI); the corresponding naphthol adducts were not observed. (see supplementary information S92-93). The feasibility of selective oxidation of the indole coupling partner by Fe(III) as a key step led us to consider whether the divergent reactivity of 5-substituted indoles observed previously might be explained by the relative oxidation potentials of these substrates. We determined the oxidation potentials of the indoles used in the synthesis of $\mathbf{3 r}-\mathbf{3 v}$ (Figure $4 \mathrm{~b}$ ) and found that the presence of electron withdrawing groups had a significant impact: the oxidation potential of the unsubstituted indole is $0.71 \mathrm{~V}$, whereas this value rises to $1.22 \mathrm{~V}$ for the 5-cyano derivative. In cases where the conversion to the heterobiaryl is low, we were able to recover unreacted indole and naphthol. This is consistent with slow oxidation of the indole limiting the rate of reaction where the oxidation potential is relatively high and is also reflected in the (incrementally) lower ratio of heterocoupled:homocoupled products when electron deficient indoles are used.

We propose the Fe(III) salt forms octahedral PyBOX complex 10 in the presence of the ligand $\mathbf{L} 4$ (see supplementary information $\mathrm{S} 90$ for mass spectrometry data consistent with this complex). This can undergo ligand exchange to form complex 11 in which the naphthol binds in a bidentate fashion (see supplementary information S91 for mass spectrometry evidence for this species). We propose that indole radicals $\mathbf{1 2}$ are generated from indoles by single electron oxidation by $\mathrm{Fe}(\mathrm{III})$ complex 10 (Figure 4c) ${ }^{41}$. This radical may be complexed (reversibly) to the Fe(II) center $^{42,43}$ which would confer extra stability to this species and potentially render it persistent ${ }^{44}$; this is consistent with our observation that the homocoupled 3,3'-bisindole is not a product of this reaction. 
a (i)

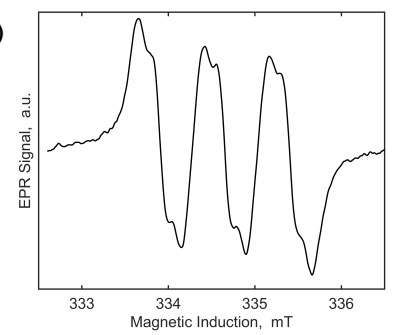

(ii)

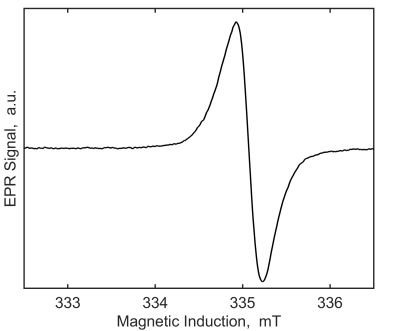

b

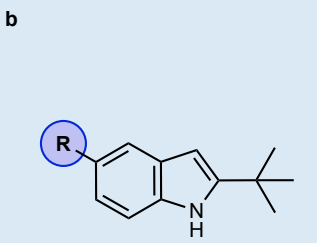

\begin{tabular}{cccc}
\hline $\mathbf{R}$ & $\boldsymbol{E}_{\text {OX }}(\mathbf{V})$ & Yield (3) & Ratio [3:4] \\
\hline $\mathrm{H}$ & 0.71 & $91 \%$ & $>50: 1$ \\
$\mathrm{~F}$ & 0.92 & $60 \%$ & $44: 1$ \\
$\mathrm{Br}$ & 0.97 & $40 \%$ & $21: 1$ \\
$\mathrm{CO}_{2} \mathrm{Me}$ & 1.00 & $40 \%$ & $18: 1$ \\
$\mathrm{CF}_{3}$ & 1.03 & $28 \%$ & $17: 1$ \\
$\mathrm{CN}$ & 1.22 & $13 \%$ & $15: 1$ \\
\hline
\end{tabular}
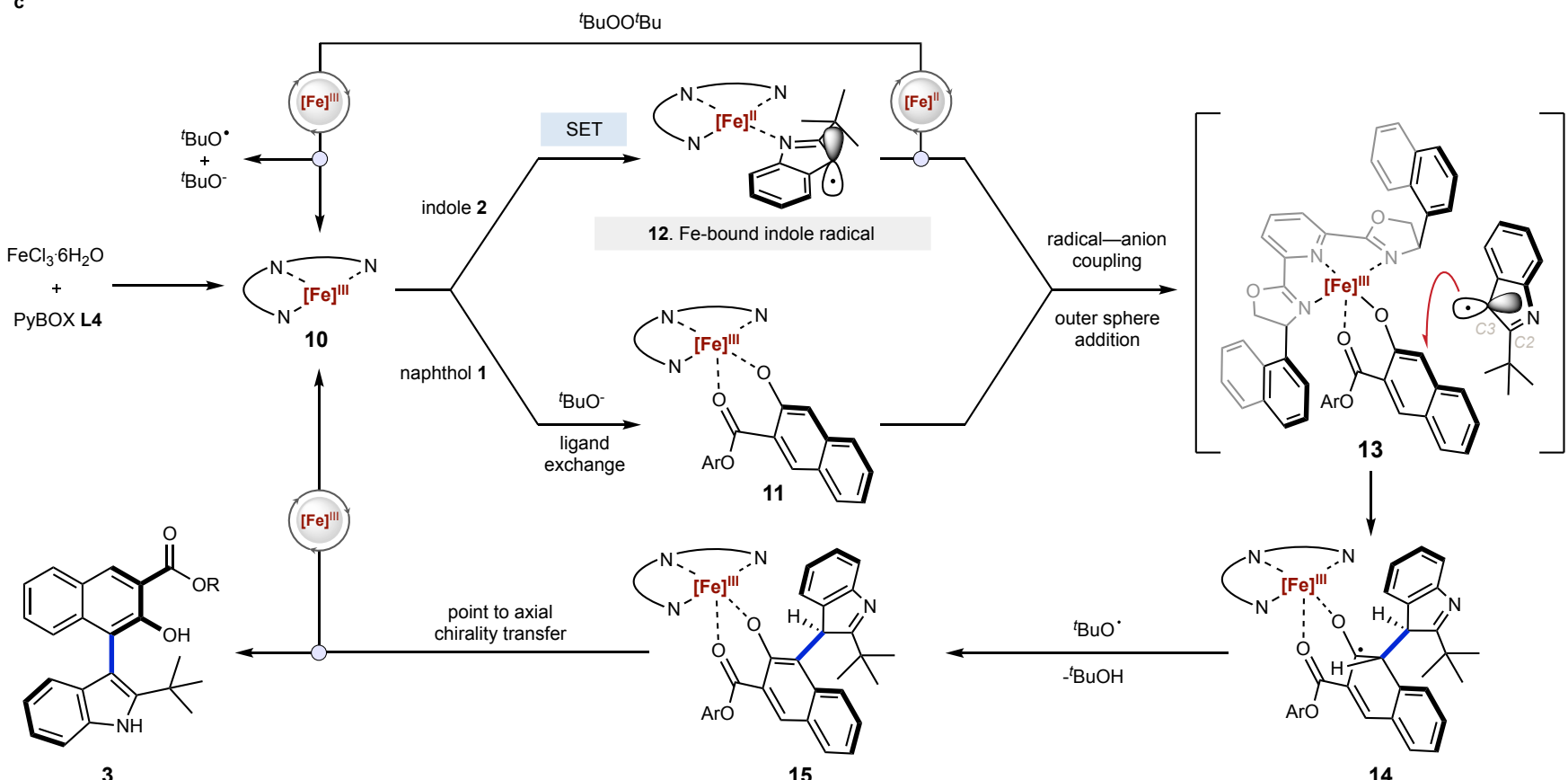

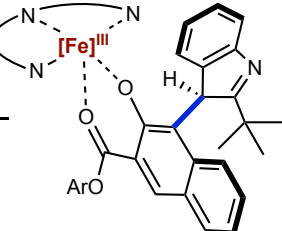

15

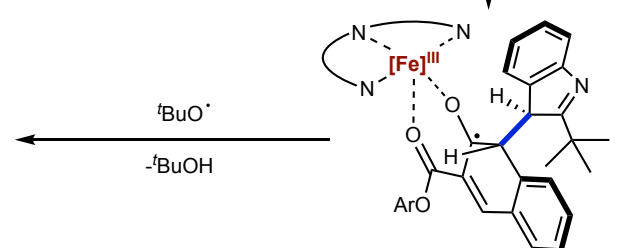

14

Figure 4: Mechanistic investigations and proposed catalytic cycle. a X-band CW-EPR at $295 \mathrm{~K}$ of (i) 2-tert-butylindole in HFIP/DCE. (ii) 2-tert-butylindole, $\mathrm{FeCl}_{3} \cdot 6 \mathrm{H}_{2} \mathrm{O}$ (0.1 eq.), ligand $\mathbf{L} 4$ (0.1 eq.), ${ }^{t} \mathrm{BuOO}{ }^{t} \mathrm{Bu}(1.0$ eq.), HFIP/DCE. b Oxidation potentials of 5-substituted indoles and yields in cross-coupling reaction with 2-isopropylphenyl 3-hydroxy-2-naphthoate 1d. Oxidation potentials measured vs $\mathrm{Ag} / \mathrm{AgCl}$. c Outline catalytic cycle. $[\mathrm{Fe}]=\mathrm{FeL}_{n}\left(\mathrm{~L}=\mathrm{Cl}^{-}, \mathrm{H}_{2} \mathrm{O}\right.$, solvent, ${ }^{t} \mathrm{BuO}^{-}$, naphthol, indole). Binding geometries of naphthol and indole partners are indicative only. $\mathrm{SET}=$ single electron transfer.

Katsuki has previously noted the necessity of two cis-sites on the Fe centre being available to enable binding of two naphthols for cross-coupling to generate BINOLs ${ }^{38}$. In our system, binding both an indole and a bidentate naphthol on the same metal centre makes the requirement for close approach of the indole radical to its naphthoate partner extremely challenging from a geometric perspective. As such we tentatively propose that the addition of the indole radical could occur via an outer sphere mechanism in which the key facially selective addition to the Fe(III) naphthol complex is directed by the $C_{2}$-symmetric ligand as in 13. Reoxidation of the $\mathrm{Fe}$ (II) complex in $\mathbf{1 2}$ to $\mathrm{Fe}$ (III) complex $\mathbf{1 0}$ may then be performed by the terminal oxidant $\left({ }^{t} \mathrm{BuOO}{ }^{t} \mathrm{Bu}\right)$. Cyclohexadienyl radical $\mathbf{1 4}$ could subsequently undergo rearomatization by hydrogen atom abstraction or oxidation to afford $15^{45,46}$, followed by ligand exchange to enable release of the enantioenriched heterobiaryl system 3 and an Fe(III) complex able to continue the catalytic cycle. Although we have demonstrated the ability of an Fe(III) species to perform the observed enantioselective oxidative coupling, this does not preclude the possibility of an $\mathrm{Fe}(\mathrm{III}) / \mathrm{Fe}(\mathrm{IV})$ cycle being operative in the catalytic reaction, and further mechanistic studies are underway.

\section{Conclusion}

We have described a process for the enantioselective synthesis of atropisomeric heterobiaryl derivatives via a direct oxidative cross-coupling that constructs the key biaryl linkage from two $\mathrm{C}-\mathrm{H}$ bonds. This reaction utilizes a cheap and abundant $\mathrm{Fe}$ catalyst in the presence of a readily available chiral PyBOX ligand to enable a remarkably chemoselective cross-coupling between indoles and phenols. We envision that this process will enable the application of these and similar heterobiaryl compounds across the fields of materials science, catalysis and medicine. 


\section{Acknowledgements}

The EPSRC has provided financial support for a postdoctoral fellowship (to X.L.; EP/R005826/1) and a studentship (to R.R.S.) via the Centre for Doctoral Training in Synthesis for Biology and Medicine (EP/L015838/1). The Centre for Advanced ESR (CAESR) is supported by the EPSRC (EP/L011972/1; EP/V036408/1) and by the OUP John Fell Fund (0007019). We are grateful to Owen Smith for X-ray crystallographic analysis and to Michael O'Donnell (Vertex) for helpful discussions.

\section{Authorship}

R.R.S., X.L. and M.D.S. conceived and designed the study; R.R.S. and X.L. performed the synthetic experiments and analyzed data for all compounds; W.M. performed the ESR study. R.R.S, X.L., W.M. and M.D.S. co-wrote the paper.

\section{Data Availability}

Crystallographic data for compound $\mathbf{8}$ has been deposited with the Cambridge Crystallographic Data Centre under deposition number CCDC 2090406. These data can be obtained free of charge from www.ccdc.cam.ac.uk/data request/cif. Any relevant data not present in the manuscript or supplementary information are available from the authors.

\section{Additional Information}

Supplementary information, X-ray data (CIF) for compound $\mathbf{8}$ and chemical compound information are available in the online version of the paper. Reprints and permissions information is available online at www.nature.com/reprints. Correspondence and requests for materials should be addressed to M.D.S.

\section{Competing Financial Interests}

The authors declare no competing financial interests.

\section{References}

1. Wencel-Delord, J., Panossian, A., Leroux, F. R., Colobert, F. Recent advances and new concepts for the synthesis of axially stereoenriched biaryls. Chem. Soc. Rev. 44, 3418-3430 (2015).

2. Cherney, A. H., Kadunce, N. T., Reisman, S. E. Enantioselective and enantiospecific transition-metal-catalyzed cross-coupling reactions of organometallic reagents to construct C-C bonds. Chem. Rev. 115, 9587-9652 (2015).

3. Loxq, P., Manoury, E., Poli, R., Deydier, E. Labande, A. Synthesis of axially chiral biaryl compounds by asymmetric catalytic reactions with transition metals. Coord. Chem. Rev. 308, 131-190 (2016).

4. Wang, Y.-B., Tan, B. Construction of axially chiral compounds via asymmetric organocatalysis. Acc. Chem. Res. 51, 534-547 (2018).

5. Ashenhurst, J. A. Intermolecular oxidative cross-coupling of arenes. Chem. Soc. Rev. 39, 540-548 (2010).

6. Yeung, C. S., Dong, V. M. Catalytic dehydrogenative cross-coupling: forming carbon-carbon bonds by oxidizing two carbon-hydrogen bonds. Chem. Rev. 111, 1215-1292 (2011).

7. Bansal, S., Shabade, A. B., Punji, B. Advances in $\mathrm{C}\left(s p^{2}\right)-\mathrm{H} / \mathrm{C}\left(s p^{2}\right)-\mathrm{H}$ oxidative coupling of (hetero)arenes using $3 \mathrm{~d}$ transition metal catalysts. Adv. Synth. Catal. 363, 1998-2022 (2021).

8. Nakajima, M., Miyoshi, I., Kanayama K., Hashimoto, S. Enantioselective synthesis of binaphthol derivatives by oxidative coupling of naphthol derivatives catalyzed by chiral diamine copper complexes. J. Org. Chem. 64, 2264-2271 (1999).

9. Hewgley, J. B., Stahl, S. S., Kozlowski, M. C. Mechanistic study of asymmetric oxidative biaryl coupling: evidence for selfprocessing of the copper catalyst to achieve control of oxidase vs oxygenase activity. J. Am. Chem. Soc. 130, 12232-12233 (2008).

10. Li, X., Yang, J., Kozlowski, M. C. Enantioselective oxidative biaryl coupling reactions catalyzed by 1,5-diazadecalin metal complexes. Org. Lett. 3, 1137-1140 (2001).

11. Egami H., Katsuki, T. Iron-catalyzed asymmetric aerobic oxidation: oxidative coupling of 2-naphthols, J. Am. Chem. Soc. 131, 6082-6083 (2009).

12. Guo, Q.-X., Wu, Z.-J., Luo, Z.-B., Liu, Q.-Z., Ye J.-L., Luo S.-W., Cun L.-F., Gong, L.-Z. Highly enantioselective oxidative couplings of 2-naphthols catalyzed by chiral bimetallic oxovanadium complexes with either oxygen or air as oxidant. J. Am. Chem. Soc. 129, 13927-13938 (2007).

13. Tian, J.-M., Wang, A.-F., Yang, J.-S., Zhao, X.-J., Tu, Y.-Q., Zhang, S.-Y., Chen, Z.-M. Copper-complex-catalyzed asymmetric aerobic oxidative cross-coupling of 2-naphthols: enantioselective synthesis of 3,3'-substituted $C_{1}$-symmetric BINOLs. Angew. Chem. Int. Ed. 58, 11023-11027 (2019). 
14. Temma, T., Habaue, S. Highly selective oxidative cross-coupling of 2-naphthol derivatives with chiral copper(I)-bisoxazoline catalysts. Tetrahedron Lett. 46, 5655-5657 (2005).

15. Zhao, X.-J., Li, Z.-H., Ding, T.-M., Tian, J.-M., Tu, Y.-Q. Wang, A.-F., Xie, Y.-Y. Enantioselective synthesis of 3,3'-disubstituted 2amino-2'-hydroxy-1,1'-binaphthyls by copper-catalyzed aerobic oxidative cross-coupling. Angew. Chem. Int. Ed. 60, 7061-7065 (2021).

16. Hayashi, H., Ueno, T., Kim, C., Uchida, T. Ruthenium-catalyzed cross-selective asymmetric oxidative coupling of arenols. Org. Lett. 22, 1469-1474 (2020).

17. Egami, H., Matsumoto, K., Oguma, T., Kunisu, T., Katsuki, T. Enantioenriched synthesis of $C_{1}$-symmetric BINOLS: iron-catalyzed cross-coupling of 2-naphthols and some mechanistic insight. J. Am. Chem. Soc. 132, 13633-13635 (2010).

18. Narute, S., Parnes, R., Toste, F. D., Pappo, D. Enantioselective oxidative homocoupling and cross-coupling of 2-naphthols catalyzed by chiral iron phosphate complexes. J. Am. Chem. Soc. 138, 16553-16560 (2016).

19. Li, T.-Z., Liu, S.-J., Tan, W., Shi, F. Catalytic asymmetric construction of axially chiral indole-based frameworks: an emerging area. Chem. Eur. J. 26, 15779-15792 (2020).

20. Qi, L. -W., Mao, J.-H., Zhang, J., Tan, B. Organocatalytic asymmetric arylation of indoles enabled by azo groups. Nature Chem. 10, 58-64 (2018).

21. Jiang, F., Chen, K.-W., Wu, P., Zhang, Y. C., Shi, F. A strategy for synthesizing axially chiral naphthyl-indoles: catalytic asymmetric addition reactions of racemic substrates. Angew. Chem. Int. Ed. 58, 15104-15110 (2019).

22. Burgett, A. W., Li, Q., Wei, Q., Harran, P. G. A concise and flexible total synthesis of (-)-diazonamide A. Angew. Chem. Int. Ed. 42, 4961-4966 (2003).

23. Nicolaou, K. E., Dalby, S. M., Li, S., Suzuki, T., Chen, D. Y. K. Total synthesis of (+)-haplophytine. Angew. Chem. Int. Ed. 48, 7616-7620 (2009).

24. Kita, Y., Tohma, H., Hatanaka, K., Takada, T., Fujita, S., Mitoh, S., Sakurai, H., Oka, S. Hypervalent iodine-induced nucleophilic substitution of para-substituted phenol ethers. Generation of cation radicals as reactive intermediates. J. Am. Chem. Soc. 116, 3684 3691 (1994)

25. Tomakinian, T., Guillot, R., Kouklovsky, C., Vincent, G. Direct oxidative coupling of N-acetyl indoles and phenols for the synthesis of benzofuroindolines related to phalarine. Angew. Chem. Int. Ed. 53, 11881-11885 (2014).

26. Liu, K., Tang, S., Huang, P., Lei, A. External oxidant-free electrooxidative [3+2] annulation between phenol and indole derivatives. Nat. Commun. 8, 1-8 (2017).

27. Evans, D. A., Dinsmore, C. J., Evrard, D. A., DeVries, K. M. Oxidative coupling of arylglycine-containing peptides. A biomimetic approach to the synthesis of the macrocyclic actinoidinic-containing vancomycin subunit. J. Am. Chem. Soc. 115, 6426-6427 (1993).

28. Libman, A., Shalit, H., Vainer, Y., Narute, S., Kozuch, S., Pappo, D. Synthetic and predictive approach to unsymmetrical biphenols by iron-catalyzed chelated radical-anion oxidative coupling. J. Am. Chem. Soc. 137, 11453-11460 (2015).

29. Gaster, E., Vainer, Y., Regev, A., Narute, S., Sudheendran, K., Werbeloff, A., Shalit, H., Pappo, D. Significant enhancement in the efficiency and selectivity of iron-catalyzed oxidative cross-coupling of phenols by fluoroalcohols. Angew. Chem. Int. Ed. 54, 4198-4202 (2015)

30. LaPlante, S. R., Edwards, P. J., Fader, L. D., Jakalian, A., Hucke, O. Revealing atropisomer axial chirality in drug discovery. ChemMedChem, 6, 505-513 (2011).

31. Hovorka, M., Gunterova, J., Závada, J. Highly selective cross-coupling of substituted naphthols: a convenient approach to unsymmetrical 1,1'-binaphthalene-2,2'-diols. Tetrahedron Lett. 31, 413-416 (1990).

32. Li, X., Hewgley, J. B., Mulrooney, C. A., Yang, J., Kozlowski, M. C. Enantioselective oxidative biaryl coupling reactions catalyzed by 1,5-diazadecalin metal complexes: Efficient formation of chiral functionalized BINOL derivatives. J. Org. Chem. 68, 5500-5511 (2003).

33. Yan, P., Sugiyama, Y., Takahashi, Y., Kinemuchi, H., Temma, T., Habaue, S. Lewis acid-assisted oxidative cross-coupling of 2naphthol derivatives with copper catalysts. Tetrahedron, 64, 4325-4331 (2008).

34. Nishiyama, H., Sakaguchi, H., Nakamura, T., Horihata, M., Kondo, M., Itoh, K. Chiral and $C_{2}$-symmetrical bis(oxazolinylpyridine)rhodium(III) complexes: effective catalysts for asymmetric hydrosilylation of ketones. Organometallics $\mathbf{8}$, 846-848 (1989).

35. Huang, X., Groves, J. T. Oxygen activation and radical transformations in heme proteins and metalloporphyrins. Chem. Rev. 118, 2491-2553 (2018).

36. McDonald, A. R., Que Jr. L. High-valent nonheme iron-oxo complexes: synthesis, structure, and spectroscopy. Coord. Chem. Rev. 257, 414-428 (2013).

37. Vershinin, V., Forkosh, H., Ben-Lulu, M., Libman, A., Pappo D. Mechanistic insights into the $\mathrm{FeCl}_{3}$-catalyzed oxidative crosscoupling of phenols with 2-aminonaphthalenes. J. Org. Chem. 86, 79-90 (2021).

38. Matsumoto, K., Egami, H., Oguma, T., Katsuki, T. What factors influence the catalytic activity of iron-salan complexes for aerobic oxidative coupling of 2-naphthols? Chem. Commun. 48, 5823-5825 (2012).

39. Niu, T., Zhang, Y. Iron-catalyzed oxidative homo-coupling of indoles via C-H cleavage, Tetrahedron. Lett. 51, 6847-6851 (2010).

40. Nagaraju, K., Ma, D. Oxidative coupling strategies for the synthesis of indole alkaloids. Chem. Soc. Rev. 47, 8018-8029 (2018).

41. Baran, P. S., Richter, J. M. Direct coupling of indoles with carbonyl compounds: short, enantioselective, gram-scale synthetic entry into the hapalindole and fischerindole alkaloid families. J. Am. Chem. Soc. 124, 7450-7451 (2004).

42. Poli R. Radical coordination chemistry and its relevance to metal-mediated radical polymerization. Eur. J. Inorg. Chem. 1513-1530. (2011).

43. Kim D., Rahaman, S. M. W., Mercado, B. Q., Poli, R., Holland P. L. Roles of iron complexes in catalytic radical alkene crosscoupling: a computational and mechanistic study. J. Am. Chem. Soc. 141, 7473-7485 (2019).

44. Leifert, D., Studer, A. The persistent radical effect in organic synthesis. Angew. Chem. Int. Ed. 59, 74-108 (2019).

45. Buxton, G. V., Langan J. R., Smith J. R. L. Aromatic hydroxylation. 8. A radiation chemical study of the oxidation of hydroxycyclohexadienyl radicals. J. Phys. Chem. 90, 6309-631 (1986).

46. Studer, A., Curran, D. P. Catalysis of radical reactions: a radical chemistry perspective, Angew. Chem. Int. Ed. 55, 58-102 (2016). 